The photograph shows the balance in repose to be perfect. It was the right eye, which was operated on. The same balance is present in all the ocular movements as well.

Yours sincerely,

G. Young.

\title{
SCLERAL STITCH IN ADVANCEMENT OPERATIONS
}

To the Editor of The British Journal of Ophthalmology

SIR,-Referring to the note by $\mathrm{Mr}$. Arthur Greene in the British Journal of Ophthalmology for March. About twenty years ago I tried the method which Mr. Greene advocates of making a hole with a discission needle and putting the ordinary curved eye needle, threaded, through the same hole. I gave it up for several reasons. Unless the hole is made unnecessarily large it is not always easy to find it and to get the curved needle through it, and the discission needle fixed in a straight handle is not so convenient for small or deeply-set eyes and does not admit of such delicate manipulation as the small straight lance-headed cutting needle which I now use, held at right angles in a straight needle holder.

I am yours faithfully,

Cl. Worth

LONDON.

March 16, 1926.

\section{THE ACCOMMODATION PROBLEM}

To the Editor of The BRitish Journal of Ophthalmology

Sir,- In the British Journal. of Ophthalmology of October 1925 , there appeared an interesting article by Dr. Hartridge on the accommodation problem. The article would have been more convincing but for a reference to the lens of the cat. The statement is made that when the lens of the cat was examined after death it was found to be in a state of accommodation.

As far back as $1886 \mathrm{Mr}$. W. Lang and I from a fairly exhaustive examination of the eyes of mammals, came to the conclusion that, 
if the majority of them had any accommodation, it was rudimentary. The observation particularly applied to the cat. Subsequent experimental investigation in Australia of a number of animals showed that with the exception of monkeys which have a fair range of accommodation, the mammals examined showed no practical evidence of the existence of accommodation within the limits of error in the methods used.

Dr. Hartridge refers to some work done with Dr. Yamada, the account of which was published in 1922 (Brit. Jl. of Ophthal., Vol. VI, p. 481). They estimated the range of accommodation of the cat by variation of the method employed by me in 1897 . They performed an iridectomy on the cat and then estimated the refraction under atropin and under eserin and obtained a maximum of $3.5 \mathrm{D}$.

In my own experimental work I always performed double and opposite iridectomies so as to eliminate completely the effect of the iris. The method was supplemented by testing the voluntary accommodation of the animal by suitable devices and by electrical stimulation of the sclero-corneal junction. The references are set out in the Ophthalmic Revierv of 1898, page 255. In that reference will be found allusions to the work of Theodore Beer, who found in a number of mammals, other than monkeys, a range of accommodation of from $1 \mathrm{D}$. to $3 \mathrm{D}$. It is pointed out there that it is difficult to be sure of a change of less than 2D., owing to experimental difficulties. Beer had previously shown that the eyes of reptiles possess an excellent accommodation apparatus and that their range of accommodation is often great. I confirmed this in the case of the Australian blue-tongued lizard, which had in the case examined a range of accommodation superior to man. Most observers who have approached the matter from the experimental point of view seem agreed that the animals named in the published accounts possess either no accommodation at all or a very small amount. Indeed, Mr. Lang and I drew attention in 1886 to the fact that in view of the degree of hypermetropia many of these animals exhibit accommodation could be of very little use to them even if they possessed it. In the course of that investigation we found no trace of accommodation except in the case of monkeys. Is it possible that in the course of evolution, possibly from reptiles to man, the accommodation became vestigial and did not revive until the anthropoid stage was reached?

Yours sincerely,

MELbOURNE.

JAMES BARRETt. 